\title{
Debunking the Myth of 'Super Bowl Sex Trafficking': Media hype or evidenced-based coverage
}

\author{
Lauren Martin and Annie Hill
}

\section{Abstract}

A large body of scholarship has described the narrow set of media narratives used to report trafficking for sexual exploitation to the public. This article examines US media coverage of human trafficking in relation to the Super Bowl, American football's championship game. Available empirical evidence does not suggest that major sporting events cause trafficking for sexual exploitation. Yet, we find that 76 per cent of US print media from 2010 to 2016 propagated the 'Super Bowl sex trafficking' narrative. Local coverage of the 2018 Super Bowl in Minneapolis, Minnesota, was different, presenting a sceptical stance toward this narrative. The article describes how this substantial shift resulted from our research group and anti-trafficking stakeholders employing an action research approach to craft a Super Bowl communication strategy that aligned with empirical evidence. Although sensationalist narratives are difficult to dislodge, the Minnesota case shows that evidence on trafficking can be effectively used to inform media and impact public perceptions, when researchers work with stakeholders on the ground. Lessons learnt are shared to enable others to replicate these results.

Keywords: human trafficking, sports, media coverage, action research, public perceptions, Super Bowl

Please cite this article as: L Martin and A Hill, 'Debunking the Myth of "Super Bowl Sex Trafficking”: Media hype or evidenced-based coverage', Anti-Trafficking Review, issue 13, 2019, pp. 13-29, https://doi.org/10.14197/atr.201219132

This is an open-access article distributed under the terms of the Creative Commons Attribution License (CC-BY). Under the CC-BY license, the public is free to share, adapt, and make commercial use of the work. Users must always give proper attribution to the authors and the Anti-Trafficking Review. 


\section{Introduction}

The Super Bowl is an annual US sporting event in which a city hosts the final game of American football to decide that season's champion. Over the past decade, media coverage of the game has included stories about so-called 'Super Bowl sex trafficking', which links this sporting event to the trafficking of women and girls for sexual exploitation.

For example, a story published shortly after the 2011 Super Bowl in the city of Dallas declared: 'reports estimated that the big game would lure 10,000 to 100,000 prostitutes to the area'. ${ }^{1}$ A 2015 story, headlined 'The Super Bowl is the largest human trafficking event in the country', claimed 'over 10,000 "prostitutes" - many of whom were trafficking victims - were brought into Miami for the Super Bowl in 2010'. ${ }^{2}$ Both of these stories link the Super Bowl with commercial sex, and with trafficking for sexual exploitation, while invoking vast numbers and various populations.

Between 2010 and 2016, we found that 76 per cent of US print media stories reported a causal or correlative link between the Super Bowl and trafficking for sexual exploitation. As we show below, the media represented 'Super Bowl sex trafficking' as a pressing problem that host cities should confront, echoing many anti-trafficking advocates and law enforcement officials. Typical anti-trafficking responses included increased policing of commercial sex, temporary ramping up of emergency services and raising public awareness.

Local media reporting on the 2018 Super Bowl in Minneapolis, Minnesota, differed substantially from previous Super Bowl coverage. Nearly 70 per cent of these print news stories presented a sceptical stance toward 'Super Bowl sex trafficking', and anti-trafficking efforts were designed to disseminate an evidencebased message. Informed media coverage matters. News stories are a trusted source of information and the public learns about trafficking primarily via the media. ${ }^{3}$

How did the shift in media coverage occur in Minnesota? Anti-trafficking stakeholders wanted their efforts to be evidence-based because they felt that action premised on previous campaigns or inaccurate information would be ineffective

1 S Solis, 'Arlington Makes Dozen of Super Bowl Prostitution Arrests', NBC DFW, 14 February 2011.

2 L Anderson, 'The Super Bowl is the largest human trafficking event in the country', Deseret News, 30 January 2015. It is not clear why the reporter used quotation marks around the word 'prostitutes'.

3 R Sanford, D Martinez and R Weitzer, 'Framing Human Trafficking: A content analysis of recent U.S. newspaper articles', Journal of Human Trafficking, vol. 2, no. 2, 2016, pp. 139-155, https://doi.org/10.1080/23322705.2015.1107341. 
at reducing harm and helping victims. Due to our expertise researching commercial sex and trafficking for sexual exploitation, stakeholders asked our research group, at the University of Minnesota's Urban Research and Outreach-Engagement Center (UROC), to examine evidence on the link between Super Bowls and 'sex trafficking'. ${ }^{4}$ In creating a partnership, we all agreed to an action research approach in order to build trust among diverse stakeholders and ensure that evidence was clearly conveyed to the media. This article offers insights into how to engage stakeholders with different ideological positions, craft evidence-based antitrafficking messages and reduce media coverage that misleads the public.

\section{The Big Game: Super Bowls and anti-trafficking preparations}

The Big Game is big business. In 2014, the US National Football League (NFL) chose Minneapolis to host the 2018 Super Bowl after a bidding process in which cities pitched their desirability and readiness to put on this huge event. ${ }^{5}$ Hosting a Super Bowl involves years of preparation and requires public and private investments in a stadium, visitor accommodations, public safety and recreational activities, including food and entertainment venues. ${ }^{6}$ The Minneapolis Super Bowl Host Committee, made up of civic and business leaders, raised more than USD 50 million to finance the Super Bowl and the regional economy received an estimated USD 370 million in new spending. ${ }^{7}$

In 2016, two years before the Minneapolis Super Bowl, an Anti-Sex Trafficking Committee (hereafter 'the Committee') was convened to prepare the region for an anticipated increase in trafficking for sexual exploitation, based on media reporting about previous Super Bowls. The Committee sought support and coordinated efforts with law enforcement, social services (e.g., emergency shelters and street outreach), volunteer training and other potentially sustainable antitrafficking initiatives. ${ }^{8}$ The Committee consisted of more than 100 representatives

4 The authors were part of a research group that the Women's Foundation of Minnesota, one of the co-chairs of the Committee, commissioned to review scholarly literature on major sporting events and 'sex trafficking' and to analyse past media reporting on 'Super Bowl sex trafficking'. Additional members of the research group included Cheyenne Syvertson, Nicolas Demm, Prerna Subramanian and Zoe Wisnoski.

5 M Wells, 'Minneapolis to Host 2018 Super Bowl', ESPN, 21 May 2014.

6 Super Bowl LII Anti-Sex Trafficking Committee, 'Minnesota's Replicable Plan to Prevent \& Disrupt Sex Trafficking During Major Events in Any City in America', July 2018, p. 4.

7 T Nelson, 'Minneapolis Super Bowl Netted \$370 Million, Report Says', MPR, 29 May 2018.

8 Super Bowl LII Anti-Sex Trafficking Committee, p. 1. 
from these sectors as well as leaders in business and government, and it raised and spent above one million dollars in 'financial contribution and in-kind donations of media and other sponsored activities.'. These efforts did not focus on trafficking for labour exploitation, although at least one non-profit organisation raised the issue and it was mentioned in some training materials. ${ }^{10}$

Researchers at UROC conduct studies of commercial sex and trafficking in Minnesota with community partners, including people who trade sex, community members, service providers, law enforcement and other groups. ${ }^{11}$ The UROC research group uses an action research (AR) approach that 'brings together action and reflection, theory and practice, in the pursuit of practical solutions to issues of pressing concern'. ${ }^{12} \mathrm{AR}$ values the knowledge and experience of all participants, co-constructs research questions and fosters shared meaning-making. AR practitioners seek to build trust and practical knowledge that can drive action. ${ }^{13}$ An AR approach is therefore particularly relevant for research with marginalised people and meaning-making about hidden and stigmatised experiences, such as commercial sex and trafficking. ${ }^{14}$

For the project outlined here, we wanted to know: What does the available empirical evidence say about major sporting events and trafficking for sexual exploitation? How should evidence inform both anti-trafficking efforts and media messaging? All partners agreed that the UROC research group would answer these questions and share the results with stakeholders.

Terminology in this research area is varied and contested. We recognise that debates, policies and beliefs about commercial sex and human trafficking are often highly-charged and polarising. The Committee, media and public in Minnesota generally used the term 'sex trafficking' to refer to trafficking for sexual exploitation.

$9 \quad$ Ibid., p. 20.

10 Super Bowl LII Anti-Sex Trafficking Committee, personal communication on 18 January 2019 with advocates, including an anti-trafficking advocate specialising in trafficking for labour exploitation.

11 For past project reports and publications, see: 'Sex Trading, Trafficking and Community Well-Being Initiative’, UROC, University of Minnesota, https://uroc.umn.edu/ sextrafficking.

$12 \mathrm{H}$ Bradbury, 'Introduction: How to situate and define action research', The SAGE Handbook of Action Research, Third Edition, SAGE Publications Inc., London, 2015.

13 E Stinger, Action Research, Fourth Edition, SAGE Publications Inc., Thousand Oaks, California, 2014.

14 L Gerassi, T Edmond and A Nichols, 'Design Strategies from Sexual Exploitation and Sex Work Studies among Women and Girls: Methodological considerations in a hidden and vulnerable population', Action Research, vol. 15, no. 2, 2017, pp. 161-176, https://doi.org/10.1177/1476750316630387. 
We also used this term to review the scholarly literature and media coverage because we were analysing the dominant discourse. This rhetorical strategy enabled stakeholders to navigate ideological differences and communicate with members of the media in terms they understood, while also working to shift the discourse on 'Super Bowl sex trafficking'. Our project did not try to resolve terminological tensions but focussed on learning from available evidence and co-creating action steps based on that shared evidentiary base. At the same time, we were well aware that terminological tensions help misleading narratives and ungrounded claims to construct the dominant discourse on trafficking, which we discuss in the media analysis below.

The UROC research group reviewed the published evidence on sporting events and trafficking for sexual exploitation and analysed US media coverage of past Super Bowls. In September 2016, we shared our findings and recommendations in a research brief and a presentation to the Committee. ${ }^{15}$ Our main finding was that available empirical evidence did not support a causal or correlative link between Super Bowls and 'sex trafficking'. In the action phase of the project, the UROC research group engaged in ongoing consultation with the Committee, joined a June 2017 press event that it sponsored and gave other print, radio and television interviews. ${ }^{16}$

Although our findings may have been surprising given past Super Bowl coverage, the Committee used our report and recommendations to create a media communication strategy. ${ }^{17}$ The final report by the Committee states it 'knew media attention on sex trafficking would increase as the Super Bowl approached. Our key goal to leverage this opportunity was to communicate our core message that sex trafficking happens 365 days a year. We also sought to dispel the myth that the Super Bowl causes a huge spike in sex trafficking. The report notes the communication strategy resulted in more than ' 34 million media impressions', which is an industry-standard estimate of the number of people exposed to communications. ${ }^{18}$

15 L Martin and A Hill, Sex Trafficking and the 2018 Super Bowl in Minneapolis: A research brief, University of Minnesota, Minneapolis, 2017, https://uroc.umn.edu/sextrafficking.

16 We also presented our review of empirical evidence and past media coverage to the Minnesota Human Trafficking Task Force and disseminated it via the UMN website.

17 Super Bowl LII Anti-Sex Trafficking Committee, p. 1.

18 Ibid., p. 8. 


\section{Evidence Review of 'Super Bowl Sex Trafficking'}

The UROC research group conducted an extensive literature review of academic articles from January 2005 to June 2016 on major sporting events and trafficking for sexual exploitation. We identified 95 potentially relevant publications of which 40 were excluded from detailed review because they were not empirical (e.g., opinion pieces, theoretical treatments or predictions). ${ }^{19}$

Scholars locate the origins of the narrative that links major sporting events and trafficking for sexual exploitation to the 2004 Athens Olympics. ${ }^{20}$ This narrative, and hyperbolic claims about commercial sex and the need for police action, recirculated at other international sporting events (e.g., World Cups and Olympic Games) and set the template for Super Bowl coverage in the United States. ${ }^{21}$ Academic articles about 'Super Bowl sex trafficking' are either premised on the assumed link or they dismiss potential links as part of a moral panic. ${ }^{22}$ US and English-language research finds that the media tends to sensationalise trafficking, emphasise rescue and connect trafficking with commercial sex and sexual exploitation only, as our media analysis confirms. ${ }^{23}$

19 Using the terms 'sex trafficking', 'prostitution', 'super bowl', 'football', and 'sporting event', we searched the following databases for relevant publications: Google Scholar, ProQuest, JSTOR, Web of Science, Scopus, EBSCOhost, Medline and PsychINFO.

20 C H Brackenridge, D Rhind and S Palmer-Felgate, 'Locating and Mitigating Risks to Children Associated with Major Sporting Events', Journal of Policy Research in Tourism, Leisure and Events, vol. 7, issue 3, 2015, pp. 237-250, https://doi.org/10.1080/1940 7963.2014.911516; International Organization for Migration (IOM), 'Trafficking in Human Beings and the 2006 World Cup in Germany', IOM Migration Research Series No. 29, 2007; see also J Flynn, 'The myth of super bowl and sex trafficking obscures real issues', San Jose Inside, 21 January 2016.

21 B Boecking et al., 'Quantifying the Relationship Between Large Public Events and Escort Advertising Behavior', Journal of Human Trafficking, vol. 5, no. 3, 2018, pp. 220-237, p. 223, https://doi.org/10.1080/23322705.2018.1458488.

22 R Finkel and M L Finkel, "The "Dirty Downside" of Global Sporting Events: Focus on human trafficking for sexual exploitation', Public Health, vol. 129, no. 1, 2015, pp. 17-22, https://doi.org/10.1016/j.puhe.2014.11.006; M Emser and S Francis, 'Media Waves and Moral Panicking: The case of the FIFA World Cup 2010', Strategic Review for Southern Africa, vol. 36, no. 2, 2014, pp. 169-180.

23 Sanford et al.; B Friedman and A Johnston, 'Blame Narratives: News discourses of sex trafficking', in C L Armstrong (ed.), Media Disparity: A gender battleground, Lexington Books, New York, 2013; A Hill, 'How to Stage a Raid: Police, media and the master narrative of trafficking', Anti-Trafficking Review, issue 7, 2016, pp. 39-55, https://doi. org/10.14197/atr.20121773. 
The scholarly literature reflects ongoing international debates about trafficking and commercial sex intertwined with issues of migration, labour, race and gender. ${ }^{24}$ The few empirical studies considering the impact of sporting events on trafficking were of two types: (1) analyses of online advertisements offering sexual services and (2) interviews with self-described sex workers in cities hosting a major sporting event. Due to the difficulties of gathering data on trafficking prevalence, such sources were identified as potential proxies to measure trafficking for sexual exploitation.

There is some empirical evidence that large events can temporarily impact the local online sex market. For example, Boecking et al. used quantitative machinelearning methods to analyse close to 37 million online sex advertisements in the United States. ${ }^{25}$ They identified 'important changes in the online escort market activity—such as increased advertisement and advertiser volume as well as increased movement to event location-correlating with a range of events and event types'. ${ }^{26}$ The changes were temporary and noted for dates and locations both with and without a large event. The Super Bowl was not unique among events correlated with an impact, which included car races, boxing matches, a Consumer Electronics Trade Show and a Memorial Day motorcycle rally. ${ }^{27}$ The Boecking et al. study therefore raises serious doubts about claims that the Super Bowl is the 'largest trafficking event' in the country.

Scholars have also analysed online sex markets in connection with Super Bowls using qualitative methods, such as interviews, and they identified similar patterns in sex ads but without the ability to place these patterns in a vast online advertising context. $^{28}$ For instance, Martin et al. observed that different events, such as concerts, conventions and athletic competitions, may be associated with a shortterm increase in the overall marketplace for sex. ${ }^{29}$

24 L Martin et al., 'Sex Trafficking and the Super Bowl: A review of the scholarly literature', September 2016, unpublished report. See also B Meshkovska et al., 'Female Sex Trafficking: Conceptual issues, current debates, and future directions', Journal of Sex Research, vol. 54, no. 4, pp. 380-395, https://doi.org/10.1080/00224499.2014.10021 26.

25 Boecking et al., p. 4.

26 Ibid., p. 16.

27 Ibid., p. 7-8.

28 M Latonero et al., Human Trafficking Online: The role of social networking sites and online classifieds, University of Southern California Annenberg Center on Communication Leadership \& Policy, Los Angeles, 2011; D Roe-Sepowitz et al., Exploring the Impact of the Super Bowl on Sex Trafficking 2015, Arizona State University School of Social Work, Office of Sex Trafficking Intervention Research, Phoenix, 2015.

29 L Martin et al., Mapping the Demand: Sex buyers in the State of Minnesota, unpublished report, 2017, available at https://uroc.umn.edu/sextrafficking. 
Conversely, extensive qualitative studies in relation to World Cups and Olympic Games did not identify increases in commercial sex or trafficking for sexual exploitation. These studies suggest that major sporting events may constrict sex markets. Deering et al. interviewed sex workers about the Vancouver Olympic Games and found 'a statistically significant reduction in the availability of clients in the Olympics period' as well as an increase in police harassment. ${ }^{30}$ Likewise, studies in South Africa related to its World Cup discerned little impact on commercial sex besides increased policing. ${ }^{31}$

After reviewing the available academic research, we concluded that 'Super Bowl sex trafficking' as reported in the news media is not empirically supported. We shared our findings with the Committee and this talking point became part of its media communication strategy. Based on the evidence, it can be claimed that online ads for sex may temporarily increase in tandem with large public events, but this claim must be qualified to clarify that ads are used as a proxy measure for trafficking and should not be understood as the same thing.

Anti-trafficking efforts spurred by sporting events tend to focus on addressing 'sex trafficking', rather than trafficking for labour exploitation. This emphasis holds true for anti-trafficking campaigns more generally. ${ }^{32}$ Yet, there is reason to investigate labour exploitation in relation to major sporting events. An increase in the number of visitors to a city, alongside the need to build facilities and prepare for and staff events, can exacerbate exploitation in sectors such as construction and hospitality. Recent research highlights trafficking, extreme abuse and the death of workers connected to Russia's 2014 Winter Olympics and Qatar's preparations for the 2022 World Cup. ${ }^{33}$ However, the media and anti-trafficking stakeholders often neglect these victims and forms of violence in favour of a focus on trafficking for sexual exploitation.

30 K N Deering et al., 'Sex Work and the Public Health Impacts of the 2010 Olympic Games', Sexually Transmitted Infections, vol. 88, no. 4, 2012, pp. 301-303, p. 302, https://doi.org/10.1136/sextrans-2011-050235.

31 W Delva et al., 'Sex Work During the 2010 FIFA World Cup: Results from a threewave cross-sectional survey', PLOS One, vol. 6, no. 12, 2010, pp. 1-6, https://doi. org/10.1371/journal.pone.0028363; M Richter et al., 'Female Sex Work and International Sport Events-No major changes in demand or supply of paid sex during the 2010 Soccer World Cup: A cross-sectional study', BMC Public Health, vol. 12, no. 1, 2012, pp. 1-12, https://doi.org/10.1186/1471-2458-12-763.

32 Sanford et al., p. 142.

33 S K Ganji, 'Leveraging the World Cup: Mega sporting events, human rights risk, and worker welfare reform in Qatar', Journal on Migration and Human Security, vol. 4, no. 4, 2016, pp. 221-259, https://doi.org/10.1177/233150241600400403; Human Rights Watch, 'Race to the Bottom: Exploitation of migrant workers ahead of Russia's 2014 Olympic Games in Sochi', 6 February 2013, https://www.hrw.org/report/2013/02/06/ race-bottom/exploitation-migrant-workers-ahead-russias-2014-winter-olympic-games. 


\section{Media Coverage of 'Super Bowl Sex Trafficking', 2010-2018}

As part of our action research approach with anti-trafficking stakeholders, we also reviewed print media to ascertain whether empirical evidence can be embedded in news stories and, if so, how. We conducted three content analyses of US print media, ${ }^{34}$ searching the terms 'prostitution', 'sex trafficking' and 'super bowl' in LexisNexis Academic and Google News. ${ }^{35}$ First, we identified 111 unduplicated stories from 31 December 2009 to 1 July 2016. Second, in order to compare past coverage and 2018 Super Bowl reporting, we conducted another review from 1 June 2017 to 4 February 2018 and identified 68 stories. Third, we analysed a sample of print news media in Minnesota after the Super Bowl from 4 February to 14 February 2018 and identified 18 stories.

We did not analyse television or radio broadcasts. Our sample included print media that used the selected keywords in the headlines. Stories that may have mentioned keywords in the text but not in the headline were excluded from the sample. Many news outlets picked up stories in whole or in part and we removed duplicates before conducting our analysis. Thus, the following review does not include the total volume of US media coverage on this topic, but it does cover the range of content.

\section{The Mass Circulation of a Myth, 2010-2016}

Three main themes were identified in the 2010-2016 sample of US print media. First, 76 per cent of the stories posited a causal or correlative link between Super Bowls and 'sex trafficking'. Second, stories supported the 'Super Bowl sex trafficking' narrative by the citational practice of quoting authoritative sources (e.g., police, politicians, anti-trafficking advocates). Third, stories circulated numbers without citation, and conflated terms, such as trafficking and prostitution or 'teen hookers' and trafficking victims.

\section{The Assumed Link}

The primary theme was the assumed link among Super Bowls, 'sex trafficking' and commercial sex. Of the 111 stories reviewed, 92 contained content affirming this link, frequently employing sensationalist language. The excerpt below is exemplary:

34 V Wilson, 'Research Methods: Content analysis', Evidence Based Library and Information Practice, vol. 6, no. 4, 2011, pp. 177-179, https://doi.org/10.18438/B86P6S.

35 Some stories were likely not captured because not all print media are accessible through these search engines. 
It's the ugly side of the Super Bowl—-the reality that America's most popular sporting event is also likely America's biggest day for sexual slavery [...]. In a cruel outplay of the economic reality of "supply and demand," it is not only local pimps who make a big profit-women and girls from all over the country are often brought in to the destination city to ensure that travellers for the big game have enough "side entertainment" available. ${ }^{36}$

This story from 2014 suggests 'sexual slavery' is the 'ugly side' of football and it invokes trafficking, sexual slavery and prostitution interchangeably. News stories also claimed the Super Bowl was the 'largest' event driving trafficking for sexual exploitation in the United States.

Only 22 stories, fewer than a quarter, presented content that cast doubt on the assumed link. Another news story, headlined ' 5 things to know about the Super Bowl and sex trafficking', illustrates this less common media coverage:

Myth-busting website Snopes said the claim that "legions of prostitutes flock to the city where the big game is being held" was "mostly false," citing a 2011 report by the Global Alliance Against Trafficking in Women [...]. The report found no evidence of a link between sex trafficking and large sporting events. $^{37}$

\section{Authoritative Sources Support the Assumed Link}

The media also quoted specific individuals and groups as experts to support the 'Super Bowl sex trafficking' narrative. These authoritative sources were quoted in relation to host cities' efforts to combat the expected increase in commercial sex and trafficking, describing security measures and policing $(\mathrm{N}=47)$, victim rescue $(\mathrm{N}=33)$, anti-trafficking public awareness campaigns $(\mathrm{N}=34)$, legislative changes $(\mathrm{N}=28)$ and social services $(\mathrm{N}=24)$. Sources spoke about arrests, referred to earlier Super Bowls and repeated previous claims about the assumed link using the authority of their positions.

During the run-up to the 2014 Super Bowl in New York, a Republican congressman discussed the potential impact on the nearby state of New Jersey:

36 R Denhollander, '16 Teens Rescued from Sex Trafficking in Super Bowl Sting', Lifenews, 7 February 2014.

37 A Pond, '5 things to know about the Super Bowl and sex trafficking', Deseret News, 6 February 2016. 
"New Jersey has a huge trafficking problem," said U.S. Rep. Chris Smith, R-N.J., who is also co-chairman of the House anti-human trafficking caucus. "One Super Bowl after another after another has shown itself to be one of the largest events in the world where the cruelty of human trafficking goes on for several weeks". ${ }^{38}$

This source contends the Super Bowl is not only one of the largest events driving trafficking in the United States, but in the world. The claim about the game's unique status is thereby even further inflated. The Associated Press recirculated the congressman's claims in its coverage.

Print media also turned to law enforcement as an authoritative source. For example, New York's Attorney General and Police Department commented on a Super Bowl 2014 pre-game sting operation against a prostitution ring, after which police checked if the women were trafficking victims. This story describes men 'flooding into the city' for sex and the Super Bowl, claiming that a commercial sex organisation 'wooed wealthy men with "party packs" of cocaine and hookers'. ${ }^{39}$ The article notes that most of the arrests were of women providing sex rather than of men buying sex or profiting from the sale of sex.

Other stories cited the Federal Bureau of Investigation (FBI) to highlight how law enforcement stings have now become a routine part of Super Bowl preparations in host cities. ${ }^{40}$ Additionally, stories mentioned efforts to change existing law. For example, a story from Indiana before the 2012 Super Bowl quoted a senator advocating for unspecified legislation because it was important to 'get something on the books' to stop trafficking and 'the sex trade. ${ }^{41}$

Anti-trafficking advocates and NGO staff were likewise interviewed as authoritative sources. Such news stories focussed on rescuing victims and providing services, while also conflating trafficking and commercial sex. ${ }^{42}$ These stories tended to amplify the voices of people calling for action against 'Super Bowl sex trafficking'

38 K Zezima and S Henry, 'NJ Works to Curb Sex Trafficking before Super Bowl; Lawmaker Calls Problem in State "Huge", The Capital, 6 January 2014.

39 G Solis, 'Huge Prostitution Ring Tackled Days Before Super Bowl, Authorities Say', DNA Info, 30 January 2014.

40 E Gaillard, 'FBI's new approach to crack down on Super Bowl Sex Trafficking', CBS News, 12 January 2016.

41 A Yeager, 'State lawmakers race to pass sex trafficking laws ahead of 2012 Super Bowl', WXIN-TV, 22 June 2011. This story was presented on air and as a print document on the station's website. It thus came up in our review of print sources.

42 No Author, 'Catholic Charities Prepares for Influx of Sex Trafficking Victims During Super Bowl', The Catholic Sun, 23 January 2015. 
without clarifying the specific agendas or political leanings of anti-trafficking advocates and organisations. For instance, a story described religious groups offering to 'serve' trafficking victims who the police arrested, implying that an arrest can lead to rehabilitation and exit from the 'lifestyle' of prostitution. ${ }^{43}$

Stories covering police and NGO interventions may mention how many people were contacted for services or outreach but rarely indicate whether the people contacted were trafficked or had any connection to the sporting event. One such story states, 'More than 70 women and children were provided services and referrals to programs to help them, according to the [FBI]', ${ }^{44}$ without providing additional information about whether the women and children were victims of trafficking or what happened to them as a result of service referrals.

\section{Conflating Terms and Inflating Numbers}

Half of the news stories $(\mathrm{N}=56)$ in our sample gave data on the Super Bowl and trafficking for sexual exploitation. Unlike the media's citational practice of quoting police, politicians and anti-trafficking advocates, these stories routinely used numerical data without citing sources. In other words, numbers were circulated but their sources were not. A story about the 2011 Super Bowl, headlined 'Dallas hunts teen sex rings before Super Bowl; big game said to attract throngs of pimps, hookers', is typical in offering numbers without reference to specific research or data sources:

The Super Bowl games annually attract as many as 10,000 teen hookers and human trafficking victims, as well as an international array of pimps seeking to rake in profits from johns, according to police and anti-trafficking organizations. ${ }^{45}$

Moreover, a headline with the terms 'sex trafficking' and 'Super Bowl' can in itself perpetuate the assumed link regardless of the story's content. Adding to the confusion and conflation, many of these stories discuss arrests for prostitution, not trafficking. ${ }^{46}$ A New Orleans newspaper ran this lead sentence: 'In an effort to combat the rampant sex trafficking that authorities say has historically accompanied the Super Bowl, a multi-agency task force arrested 85 people during

43 A Hill, 'Demanding Victims: The sympathetic shift in British prostitution policy', in C R Showden and S Majic, Negotiating Sex Work: Unintended consequences of policy and activism, University of Minnesota Press, Minneapolis, 2014.

44 S A Feeney, 'Pimps Arrested, Victims Rescued in Super Bowl-Related Sex Trafficking', McClatchy-Tribune Business News, 4 February 2014.

45 P Caulfield, 'Dallas hunts teen sex rings before Super Bowl; big game said to attract thousands of pimps, hookers', Daily News, 1 February 2011.

46 M Casserly, 'Sex and the Super Bowl: Indianapolis puts spotlight on teen sex trafficking', Forbes, 2 February 2012. 
the week leading up to Sunday's game'. ${ }^{47}$ The sentence suggests that the 85 arrests refer to 'rampant sex trafficking'; however, the full story lists the criminal charges as 'human trafficking, prostitution, pandering, narcotics and weapons' and does not give the number of people actually charged with trafficking.

Only a minority of news stories addressed the confusion over terms and numbers. This 2016 story dealt directly with the confusion caused by conflation:

The problem with the Super Bowl "trafficking" numbers is that not all the victims were trafficked. [FBI agent] Fairries tells SF Weekly that some of the 129 prostitutes the [FBI] "contacted" were just independent sex workers conducting business as usual. But much like the [San Francisco Police Department], which counts every sex worker it encounters as trafficked, the FBI considers all prostitutes "victims". ${ }^{48}$

Terminological conflation was common to how sources, generally perceived by the public as authoritative, framed trafficking and anti-trafficking efforts. The three themes we identified in print media coverage- the assumed link, the citation of authoritative sources, and the confusion over terms and numbers-shape public perceptions of trafficking in ways that do not align with available empirical evidence. We now turn from this analysis of our 2010-2016 sample to the substantial shift in media coverage of the Minneapolis Super Bowl.

\section{Media Coverage of the Minneapolis Super Bowl}

Print media coverage of the 2018 Super Bowl engaged the themes above, but within a different frame. The majority of the 68 articles ( 57 per cent) prior to the game (1 June 2017 to 4 February 2018) displayed doubt about 'Super Bowl sex trafficking'. ${ }^{49}$ Additionally, the eighteen stories in the two weeks after the game quoted law enforcement in ways that cast uncertainty on the 'Super Bowl sex trafficking' narrative. In total, the majority of local print coverage (66 per cent) did not support the narrative or established themes. This finding demonstrates a

47 N Martin, 'Authorities Nab 85 in Effort to Combat Super Bowl Sex Trafficking', The Times-Picayune, 7 February 2013.

48 J Lynbarger, 'Massaging the Super Bowl's Sex Trafficking Stats', SF Weekly, 17 February 2016.

49 The Anti-Sex Trafficking Committee found that there were 141 published stories related to their efforts from June 2017 through 5 February 2018. We identified far fewer. There are two reasons for the difference. First, our data examined only news stories published in Minnesota. Second, news stories are often recycled and we eliminated duplicates for our analysis. 
major change in media communication to the public about trafficking.

Most of the stories in the Minnesota sample characterised 'sex trafficking' as an activity that can happen all year rather than as something specifically tied to the Super Bowl. Indeed, 48 out of the 68 stories used the phrase 'year round'. Fifteen stories used the phrase ' 365 days a year' in relation to trafficking for sexual exploitation, which echoed one of the Committee's main talking points. This point stressed the need for long-term services for sexually-exploited women instead of episodic interventions connected to events like the Super Bowl. This type of media coverage was not restricted to the 2018 Super Bowl, but only appeared in seven stories in the 2010-2016 sample. The increased use of this frame underscores the impact of the Committee's efforts to influence media coverage to more closely match evidence gathered by our research group.

Unlike previous Super Bowl coverage, most Minnesota stories debunked the 'Super Bowl sex trafficking' narrative $(\mathrm{N}=23)$ or evinced a sceptical stance $(\mathrm{N}=16)$. This deeper contextualisation was typical:

As the Twin Cities prepares to host Super Bowl LII, planning has long been underway to address any accompanying uptick in prostitution or sex trafficking. While people elsewhere have made claims that the Super Bowl is the biggest time for sex trafficking, a University of Minnesota report noted "the Super Bowl does not appear to have the largest impact". ${ }^{50}$

Seventeen news stories published in the months before the Super Bowl cited our research. These stories quoted the UROC research group, the Women's Foundation of Minnesota, other members of the Committee and/or the official Super Bowl Host Committee.

Slightly more than 30 per cent of media coverage contained content that supported the 'Super Bowl sex trafficking' narrative $(\mathrm{N}=22)$, a substantial drop compared to the 76 per cent between 2010 and 2016. Stories in Minnesota also used less sensationalist language and fewer inflated numbers compared to previous coverage.

Yet, a notable portion continued to focus on public awareness efforts and law enforcement. About a third ( $\mathrm{N}=29)$ mentioned the Committee's response plan, including the awareness campaigns 'Don't Buy It' aimed at people who purchase sex and 'I am Priceless' aimed at youth. These stories noted plans to improve access to social services, shelter beds and street outreach, and create a more

50 M Gottfried, 'Super Bowl the Biggest Time for Sex Trafficking? That's a Myth. Here's What Happens Every Day in the Twin Cities', Twin Cities Pioneer Press, 29 January 2018. 
coordinated police response to target traffickers and people who purchase sex, while avoiding the arrest of trafficking victims and sex workers.

All eighteen stories published after the Super Bowl reported on police sting operations in the run-up to game day. All but one mentioned a ten-day sting operation by the Minneapolis and St. Paul Sheriffs' offices with the Minnesota Bureau of Criminal Apprehension.

Nevertheless, post-game coverage supported the sceptical view and debunked claims that traffickers and men who want to purchase sex came from out of state and that women were trafficked to Minnesota for the Super Bowl. Some stories $(\mathrm{N}=12)$ highlighted that men arrested for trying to purchase sex were local. They used phrases like 'men in our own communities' and they did not recirculate the established theme that women and children were 'brought in' from elsewhere or that traffickers 'gravitate' to host cities. Less frequently, stories cited law enforcement participating in myth busting, such as when a Shakopee Police Sergeant stated, 'In our operations we just didn't find the connections to the Super Bowl'. ${ }^{51}$

\section{How to Build Evidence-Based Media Coverage of Trafficking}

In the absence of evidence, the 'Super Bowl sex trafficking' narrative influences how the public, politicians, police and other stakeholders comprehend trafficking and therefore how they choose to intervene in commercial sex markets. From 2010 to 2016, the vast majority of US print media presented authoritative sources circulating claims about sporting events and commercial sex while conflating trafficking, commercial sexual exploitation (such as economic coercion) and consensual sex work. Although Super Bowl coverage occasionally questioned this narrative, the sceptical view was drowned in a sea of stories that suggested a natural, obvious or inevitable link.

News media misrepresentations amplify, and are amplified by, abundant trafficking narratives in film, television and anti-trafficking awareness campaigns. ${ }^{52}$ The linkage of sporting events and trafficking reflects and reinforces broader narratives about sexuality and sexual exploitation that depict men as aggressive and autonomous, and women as victims in need of rescue or criminals who should

51 D Winter, '16 Arrests Made in Shakopee During Super Bowl Sex Trafficking Sting', Shakopee Valley News, 9 February 2018.

52 L Fedina, 'Use and Misuse of Research in Books on Sex Trafficking: Implications for interdisciplinary researchers, practitioners, and advocates', Trauma, Violence and Abuse, vol. 16, no. 2, 2015, pp. 188-198, https://doi.org/10.1177/1524838014523337. 
be arrested. The Super Bowl adds stereotypes about masculinity, male fans and the purchase of sex that represent commercial sex in ways that obscure the wide range of people who sell sex (including boys, men and transgender people). The myth of 'Super Bowl sex trafficking' also depends on cultural narratives that stereotype people in the sex trade and thereby ignore context, a wide range of experiences and the complex realities of people's lives. Responses to these narratives lead to arrest, stigma and missed opportunities to inform the public and avoid the harms caused by misguided interventions.

Yet, we found that empirical evidence can be used effectively to inform media, debunk myths and propel action. The successful shift in media coverage in Minnesota during the 2018 Super Bowl emerged from a partnership between researchers and anti-trafficking stakeholders. We all agreed that media coverage on this topic needed to be better informed and that sensationalist stories can mislead the public and harm the people whom anti-trafficking efforts seek to support. We thus co-created a media communication strategy based on an action research approach. Through the AR approach, the UROC research group reviewed the evidence on major sporting events and 'sex trafficking', and these data guided the subsequent communication strategy. The partnership of researchers, antitrafficking advocates, law enforcement and civic leaders adhered to this strategy by employing talking points that were clear and accessible to the media. Addressing the 'Super Bowl sex trafficking' narrative with an AR approach proved vital because it was evidence-based, collaborative and directed at concrete action.

The fact that stakeholders came together in 2016 specifically to confront trafficking related to the Super Bowl suggests that Committee members and other Minnesota stakeholders believed that there would be an increase in commercial sexual activity and trafficking for sexual exploitation. The Women's Foundation of Minnesota, which commissioned the research, and other members of the Committee expressed a desire to ground their work in evidence in order to have a positive impact on preventing sexual exploitation, with the belief that nuanced understanding is required for effective action. Within the context of 'fake news' and post-truth claims, a cross-stakeholder commitment to evidence and accurate reporting about the Super Bowl and 'sex trafficking' was exceptional, especially when the evidence contradicted a dominant discourse.

Our partnership offers a potential counterpoint to what Elizabeth Bernstein termed a 'coalition of strange bedfellows', wherein groups with competing agendas establish ideological convergence in relation to trafficking. ${ }^{53}$ Bernstein studied

53 E Bernstein, 'Militarized Humanitarianism Meets Carceral Feminism: The politics of sex, rights, and freedom in contemporary antitrafficking campaigns', Signs: Journal of Women in Culture and Society, vol. 36, no. 1, 2010, pp. 45-71, p. 47, https: //doi.org/10.1086/652918. 
the unlikely alliance between evangelical Christians and feminists advocating for the abolition of commercial sex and increased criminal penalties for traffickers, people who purchase sex and sex workers who do not comply with 'rehabilitation'. By contrast, our partnership did not share a commitment to 'carceral paradigms' premised on the rescue or punishment of women and recrimination of men. ${ }^{54}$ Instead, it brought interested parties together with the aim of reviewing, respecting and acting on an evidence base. This shared aim fostered a clear method and subsequent message among diverse stakeholders that resulted in a successful media intervention.

\section{Acknowledgements}

We are deeply grateful to Cheyenne Syvertson MSW who was the lead research assistant on this project at UROC. Our gratitude also goes to Borislav Gerasimov and the anonymous reviewers for insightful suggestions that helped to improve the article. This research developed from our collaboration with many people working to reduce exploitation in the sex trade. We thank them for their partnership and trust.

Lauren Martin PhD is the Director of Research at the University of Minnesota's Urban Research Outreach-Engagement Center and affiliated faculty with the Humphrey School of Public Affairs. She directs the UROC initiative on sex trading, has authored community and scholarly publications, and helped to develop programmes, prevention efforts and policy related to sex trading and trafficking. She is currently writing a book on trustworthy knowledge production, action research and sex trading. Email: mart2114@umn.edu

Annie Hill PhD is an Assistant Professor in the Department of Rhetoric and Writing at the University of Texas, Austin. Her scholarly publications focus on sexual violence, sex work and trafficking in the United States and the United Kingdom. She is on research teams for a Sexual Violence Prevention Collaboratory and a Sex Trading, Trafficking and Community Well-Being Initiative. She is also a curator for The Gender Policy Report. Email: anniehill@utexas.edu 